\title{
SGK1-dependent stimulation of vascular smooth muscle cell osteo-/chondrogenic transdifferentiation by interleukin-18
}

\author{
Nadeshda Schelski ${ }^{1}$ Trang T. D. Luong ${ }^{1} \cdot$ Florian Lang ${ }^{2} \cdot$ Burkert Pieske ${ }^{1,3,4,5} \cdot$ Jakob Voelk| ${ }^{1,5,6} \cdot$ loana Alesutan ${ }^{1,3,5}$
}

Received: 19 October 2018 / Revised: 4 January 2019 / Accepted: 13 January 2019 / Published online: 31 January 2019

(C) The Author(s) 2019

\begin{abstract}
The serum- and glucocorticoid-inducible kinase 1 (SGK1) is a key regulator of osteo-/chondrogenic transdifferentiation and subsequent calcification of vascular smooth muscle cells (VSMCs). The phenotypical transdifferentiation of VSMCs is associated with increased interleukin-18 (IL-18) levels and generalized inflammation. Therefore, the present study investigated the possible involvement of SGK1 in IL-18-induced vascular calcification. Experiments were performed in primary human aortic smooth muscle cells (HAoSMCs) treated with recombinant human IL-18 protein in control or high phosphate conditions and following SGK1 knockdown by siRNA or pharmacological inhibition of SGK1, PI3K, and PDK1. As a result, IL-18 treatment increased SGK1 mRNA and protein expression in HAoSMCs. IL-18 upregulated SGK1 mRNA expression in a dose-dependent manner. This effect was paralleled by upregulation of the mRNA expression of MSX2 and CBFA1, osteogenic transcription factors, and of tissue-nonspecific alkaline phosphatase ( $A L P L)$, an osteogenic enzyme, as markers of increased osteo-/ chondrogenic transdifferentiation. Phosphate treatment increased $S G K 1$ and osteogenic markers mRNA expression as well as ALPL activity and induced calcification of HAoSMCs, all effects significantly augmented by additional treatment with IL-18. Conversely, silencing of SGK1 or cotreatment with the SGK1 inhibitor EMD638683 blunted the effects of IL-18 on osteo-/ chondrogenic transdifferentiation and calcification of HAoSMCs. The procalcific effects of IL-18 were similarly suppressed in the presence of PI3K or PDK1 inhibitors. In conclusion, SGK1 expression is upregulated by IL-18 in VSMCs and SGK1 participates in the intracellular signaling of IL-18-induced osteo-/chondrogenic transdifferentiation of VSMCs. Thus, SGK1 may serve as therapeutic target to limit the progression of medial vascular calcification during vascular inflammation.
\end{abstract}

Keywords SGK1, interleukin-18 · PI3K · Vascular calcification · Osteo-/chondrogenic signaling · Vascular smooth muscle cells

\section{Introduction}

Medial vascular calcification is frequently observed in aging, diabetes mellitus, atherosclerosis, and most extensively in chronic kidney disease (CKD) [32, 44]. In large arteries, vascular calcification may lead to increased stiffness, elevated pulse pressure and, thus, to cardiac hypertrophy and impaired coronary perfusion [18, 20]. Accordingly, vascular calcification is associated with an

Nadeshda Schelski and Trang T. D. Luong contributed equally and thus share first authorship.

This article is part of the Topical Collection on Molecular and cellular mechanisms of disease

Jakob Voelkl

jakob.voelk1@jku.at

1 Department of Internal Medicine and Cardiology, Charité Universitätsmedizin Berlin, Campus Virchow-Klinikum, Augustenburgerplatz 1, 13353 Berlin, Germany

2 Department of Physiology I, Eberhard-Karls University, Wilhelmstr. 56, 72076 Tübingen, Germany
3 Berlin Institute of Health (BIH), Anna-Louisa-Karsch 2, 10178 Berlin, Germany

4 Department of Internal Medicine and Cardiology, German Heart Institute Berlin, Augustenburger Platz 1, 13353 Berlin, Germany

5 DZHK (German Centre for Cardiovascular Research), partner site Berlin, Hessische Str. 3-4, 10115 Berlin, Germany

6 Institute for Physiology, Johannes Kepler University Linz, Altenberger Strasse 69, 4040 Linz, Austria 
increased risk for cardiovascular events and cardiovascular and all-cause morbidity and mortality in CKD [35, 41, 44].

Vascular calcification is an active pathological process, promoted mainly by osteo-/chondrogenic transdifferentiation of vascular smooth muscle cells (VSMCs) $[18,28]$. In CKD, various pathological factors, most importantly phosphate, induce the osteo-/chondrogenic transdifferentiation of VSMCs via complex intracellular signaling pathways $[3,18,29,34,54]$. These cells are characterized by increased expression and activity of osteogenic transcription factors such as msh homeobox 2 (MSX2) [11] and core-binding factor $\alpha-1$ (CBFA1) [9] as well as osteogenic enzymes such as tissue-nonspecific alkaline phosphatase (ALPL) [31, 43]. The osteoblast- and chondroblast-like VSMCs promote mineralization of vascular tissue via mechanisms similar to physiological bone calcification [39]. Inflammatory processes are involved in osteo-/chondrogenic transdifferentiation of VSMCs and vascular calcification in CKD $[18,46]$.

Increased plasma levels of interleukin-18 (IL-18), a proinflammatory cytokine [17], are frequently observed in CKD patients $[12,16]$ and associated with medial vascular calcification [23, 62]. Recent reports indicate that IL-18 enhances osteo-/chondrogenic transdifferentiation of VSMCs [62], but the intracellular signaling pathways contributing to these procalcific effects are still ill-defined.

The serum- and glucocorticoid-inducible kinase 1 (SGK1) is upregulated at transcriptional level by various pathologic factors known to trigger osteo-/chondrogenic transdifferentiation and calcification of VSMCs, such as hyperphosphatemia, mineralocorticoid or glucocorticoid excess, hyperglycemia, or inflammatory cytokines [25, 56-58]. SGK1 has been shown to contribute to the pathophysiology of several disorders [25, 30], including cardiac remodeling [53, 56, 57], hypertension [27], stroke [22], diabetes mellitus [26], kidney disease [10,55], or inflammation [15]. SGK1 promotes osteo-/chondrogenic transdifferentiation of VSMCs [58]. Overexpression of constitutively active SGK1, but not inactive SGK1, is sufficient to induce osteo-/ chondrogenic transdifferentiation of VSMCs [58]. Conversely, inhibition, deficiency, or knockdown of SGK1 are able to inhibit osteo-/chondrogenic transdifferentiation and calcification of VSMCs during phosphate exposure [58].

Therefore, the present study explored the effects of IL-18 on SGK1 expression in VSMCs as well as the possible involvement of SGK1 in IL-18-induced osteo-/chondrogenic transdifferentiation and calcification of VSMCs in vitro.

\section{Methods}

\section{Cell culture of primary human aortic smooth muscle cells}

Primary human aortic smooth muscle cells (HAoSMCs, Thermo Fisher Scientific) [2, 5, 34] were routinely cultured in medium containing Waymouth's MB 752/1 medium and Ham's F-12 nutrient mixture (Thermo Fisher Scientific) in a 1:1 ratio, supplemented with 10\% FBS (Thermo Fisher Scientific), $100 \mathrm{U} / \mathrm{ml}$ penicillin, and $100 \mu \mathrm{g} / \mathrm{ml}$ streptomycin (Thermo Fisher Scientific). HAoSMCs were grown to confluence and used in all experiments from passages 4 to 10 .

Where indicated, HAoSMCs were transfected with $10 \mathrm{nM}$ SGK1 siRNA (ID no. s740, Thermo Fisher Scientific) or with $10 \mathrm{nM}$ negative control siRNA (ID no. 4390843, Thermo Fisher Scientific) using siPORT amine transfection agent (Thermo Fisher Scientific) according to the manufacturer's protocol [58]. The cells were used $48 \mathrm{~h}$ after transfection and silencing efficiency were analyzed by quantitative RT-PCR.

HAoSMCs were treated for $24 \mathrm{~h}$ (qRT-PCR), 7 days (ALPL activity), or 11 days (calcification) with $2 \mathrm{mM} \beta$ glycerophosphate (Sigma-Aldrich), the indicated concentrations of recombinant human interleukin-18 protein (R\&D Systems), $50 \mu \mathrm{M}$ SGK1 inhibitor EMD638683 (stock in DMSO) [57, 58], 1 MM LY294002 (Enzo Life Sciences, stock in DMSO), $100 \mathrm{nM}$ wortmannin (Enzo Life Sciences, stock in DMSO) [21], or $1 \mu \mathrm{M}$ PDK1 inhibitor GSK2334470 (Cayman Chemical, stock in DMSO). Equal amounts of vehicle were used as control. Treatment with calcification medium containing $10 \mathrm{mM} \beta$-glycerophosphate and $1.5 \mathrm{mM}$ $\mathrm{CaCl}_{2}$ (Sigma-Aldrich) for 11 days was used for quantification of mineralization and Alizarin red staining $[52,59]$. Fresh media with agents were added every $2-3$ days.

\section{Quantification of calcium deposition}

HAoSMCs were decalcified in $0.6 \mathrm{M} \mathrm{HCl}$ for $24 \mathrm{~h}$ at $4{ }^{\circ} \mathrm{C}$. Calcium content in the supernatant was determined by using QuantiChrom Calcium assay kit (BioAssay Systems) according to the manufacturer's protocol. HAoSMCs were lysed with $0.1 \mathrm{M} \mathrm{NaOH} / 0.1 \%$ SDS and protein concentration was measured by the Bradford assay (Bio-Rad Laboratories). The results are shown normalized to total protein concentration [4].

\section{Alizarin red staining}

To visualize calcification, HAoSMCs were fixed with $4 \%$ paraformaldehyde and stained with $2 \%$ Alizarin red $(\mathrm{pH} 4.5)$ [3]. The calcified areas are shown as red staining.

\section{ALPL activity assay}

ALPL activity in HAoSMCs was determined by using the ALP colorimetric assay kit (Abcam) according to the manufacturer's protocol. The results are shown normalized to total protein concentration measured by the Bradford assay (BioRad Laboratories) [5, 54]. 


\section{Quantitative RT-PCR}

Total RNA was isolated from HAoSMCs by using Trizol Reagent (Thermo Fisher Scientific) according to the manufacturer's instructions $[1,33,55]$. Reverse transcription of $2 \mu \mathrm{g}$ total RNA was performed using oligo $(\mathrm{dT})_{12-18}$ primers (Thermo Fisher Scientific) and SuperScript III Reverse Transcriptase (Thermo Fisher Scientific). Quantitative RTPCR was performed with the iCycler $\mathrm{iQ}^{\mathrm{TM}}$ Real-Time PCR Detection System (Bio-Rad Laboratories) and $\mathrm{iQ}^{\mathrm{TM}} \mathrm{Sybr}$ Green Supermix (Bio-Rad Laboratories) according to the manufacturer's instructions. The specificity of the PCR products was confirmed by analysis of the melting curves. All PCRs were performed in duplicate and relative mRNA expression was calculated by the $2^{-\Delta \Delta \mathrm{Ct}}$ method using GAPDH as housekeeping gene, normalized to the control group. The following human primers were used (Thermo Fisher Scientific; $5^{\prime} \rightarrow 3^{\prime}$ orientation):

$A L P L$ fw: GGGACTGGTACTCAGACAACG;

$A L P L$ rev: GTAGGCGATGTCCTTACAGCC;

CBFA 1 fw: GCCTTCCACTCTCAGTAAGAAGA;

CBFA1 rev: GCCTGGGGTCTGAAAAAGGG;

GAPDH fw: GAGTCAACGGATTTGGTCGT;

GAPDH rev: GACAAGCTTCCCGTTCTCAG;
$M S X 2$ fw: TGCAGAGCGTGCAGAGTTC;

$M S X 2$ rev: GGCAGCATAGGTTTTGCAGC;

SGK1 fw: GCAGAAGAAGTGTTCTATGCAGT;

SGK1 rev: CCGCTCCGACATAATATGCTT.

\section{Western blotting}

HAoSMCs were lysed with ice-cold IP lysis buffer (Thermo Fisher Scientific) containing complete protease and phosphatase inhibitor cocktail (Thermo Fisher Scientific) $[45,58]$. After centrifugation at $10000 \mathrm{rpm}$ for $5 \mathrm{~min}$, protein concentrations were measured by the Bradford assay (Bio-Rad Laboratories). Equal amounts of proteins were boiled in Roti-Load1 Buffer (Carl Roth $\mathrm{GmbH})$ at $100{ }^{\circ} \mathrm{C}$ for $10 \mathrm{~min}$, separated on SDSpolyacrylamide gels and transferred to PVDF membranes. The membranes were incubated overnight at $4{ }^{\circ} \mathrm{C}$ with primary rabbit anti-SGK1 antibody (1:1000 dilution, cell signaling) or rabbit anti-GAPDH antibody (1:1000 dilution, cell signaling) and then with secondary anti-rabbit HRP-conjugated antibody (1:1000 dilution, cell signaling) for $1 \mathrm{~h}$ at room temperature. For loading controls, the membranes were stripped in stripping buffer (Thermo Fisher Scientific) at room temperature for $10 \mathrm{~min}$.
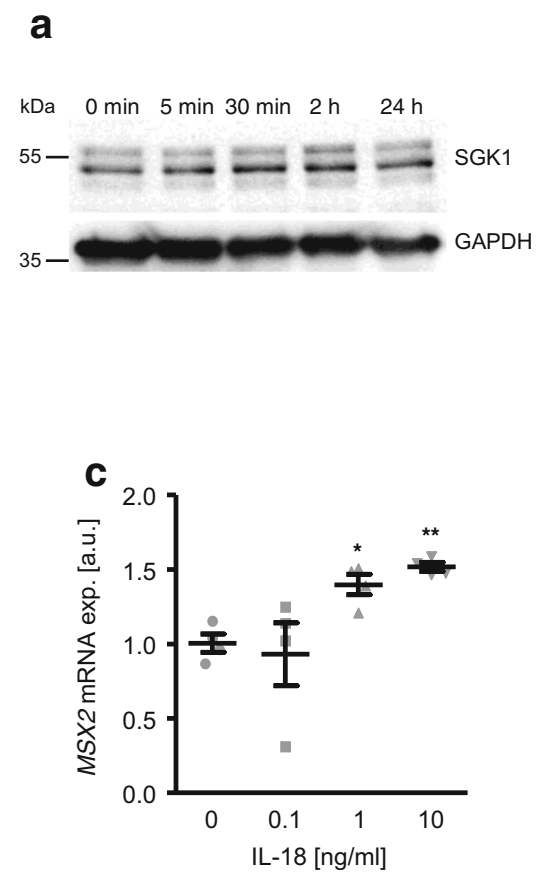

Fig. 1 Interleukin-18 upregulates $S G K 1$ and osteogenic markers expression in primary human aortic smooth muscle cells in a dosedependent manner. a Representative original Western blots and scatter dot plots and arithmetic means $\pm \operatorname{SEM}(n=8$; arbitrary units, a.u.) of normalized SGK1/GAPDH protein ratio in HAoSMCs following treatment for the indicated times with $10 \mathrm{ng} / \mathrm{ml}$ recombinant human
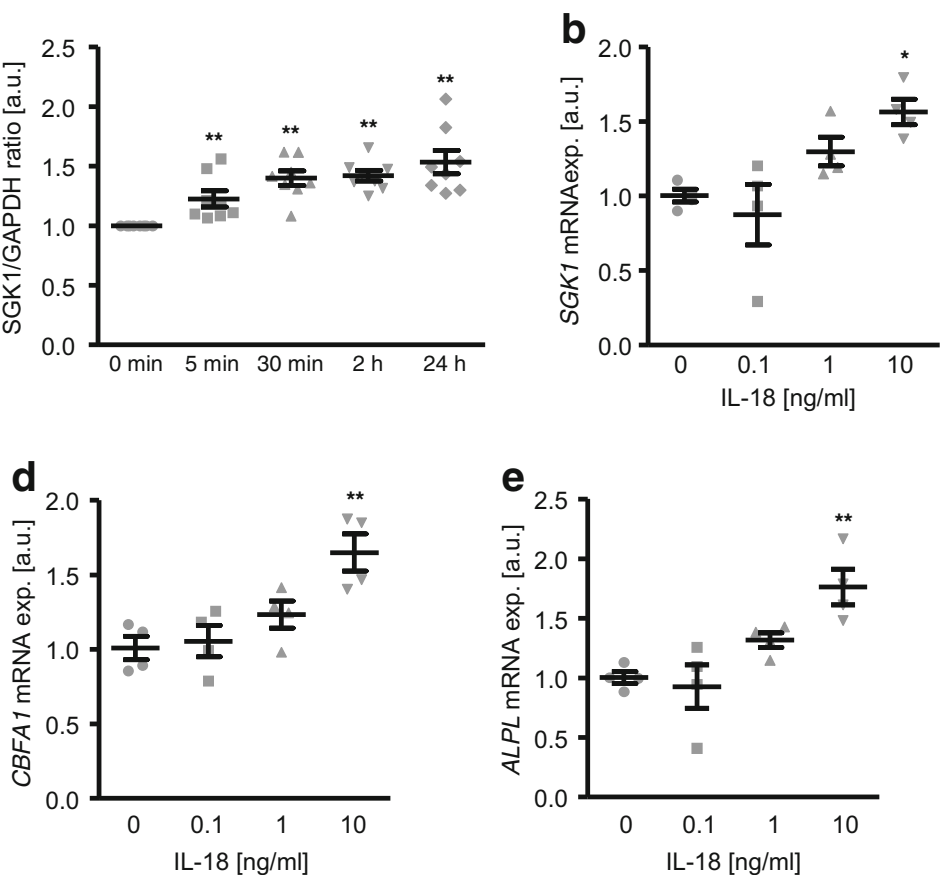

interleukin-18 protein (IL-18). b-e Scatter dot plots and arithmetic means $\pm \operatorname{SEM}(n=4$; a.u.) of $S G K 1$ (b), MSX2 (c), CBFA1 (d), and ALPL (e) relative mRNA expression in HAoSMCs following treatment for $24 \mathrm{~h}$ with control (CTR) or with the indicated concentrations of recombinant human interleukin-18 protein (IL-18, $0.1-10 \mathrm{ng} / \mathrm{ml}) . *(p<0.05)$, $* *(p<0.01)$ statistically significant vs. control-treated HAoSMCs 


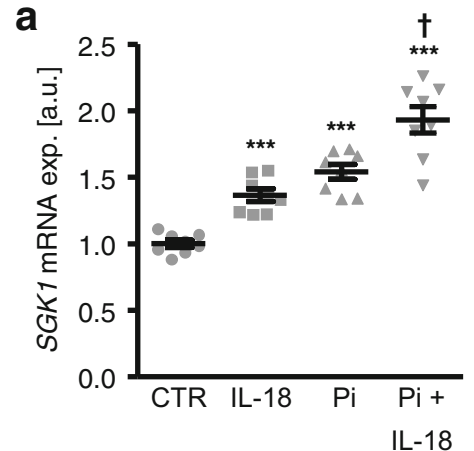

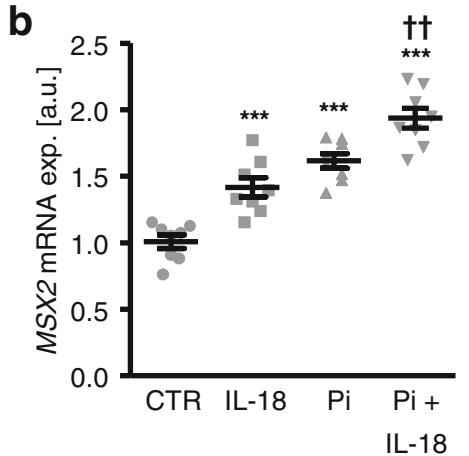

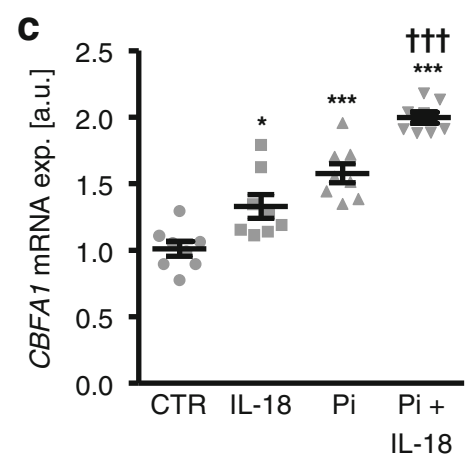

Fig. 2 Interleukin-18 augments phosphate-induced $S G K 1$ expression and osteogenic signaling in primary human aortic smooth muscle cells. a-d Scatter dot plots and arithmetic means $\pm \operatorname{SEM}(n=8$, arbitrary units, a.u.) of $S G K 1$ (a), MSX2 (b), CBFA1 (c), and ALPL (d) relative mRNA expression in HAoSMCs following treatment for $24 \mathrm{~h}$ with control or with $2 \mathrm{mM} \beta$-glycerophosphate ( $\mathrm{Pi}$ ) without or with additional treatment with $10 \mathrm{ng} / \mathrm{ml}$ recombinant human interleukin-18 protein (IL-18). e Scatter dot d

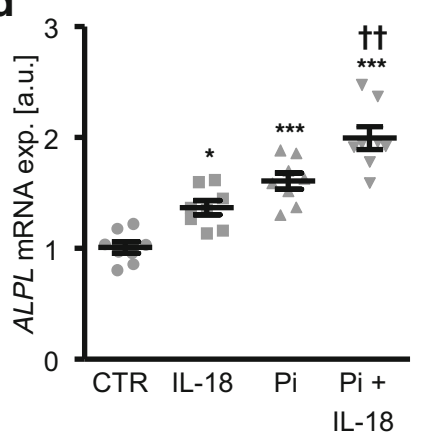

e

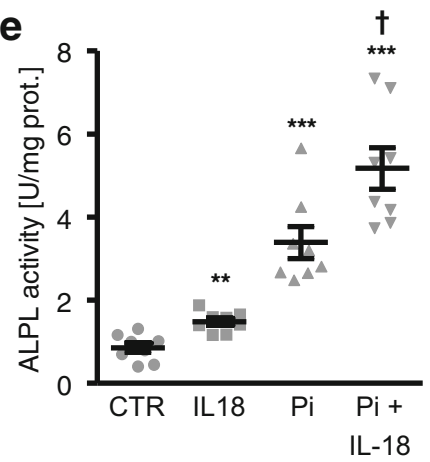

plots and arithmetic means $\pm \operatorname{SEM}(n=8, \mathrm{U} / \mathrm{mg}$ protein $)$ of ALPL activity in HAoSMCs following treatment for 7 days with control or with $2 \mathrm{mM}$ $\beta$-glycerophosphate (Pi) without or with additional treatment with $10 \mathrm{ng} / \mathrm{ml}$ recombinant human interleukin-18 protein (IL-18). $*(p<0.05), * *(p<0.01), * * *(p<0.001)$ statistically significant vs. control-treated HAoSMCs; $\uparrow(p<0.05), \uparrow \dagger(p<0.01)$, $\dagger \dagger+(p<0.001)$ statistically significant vs. HAoSMCs treated with Pi alone

\section{Statistics}

(Thermo Fisher Scientific), and bands were quantified by using ImageJ software. Results are shown as the ratio of total protein to GAPDH normalized to the control group.

Data are shown as scatter dot plots and arithmetic means \pm SEM. $N$ indicates the number of independent experiments
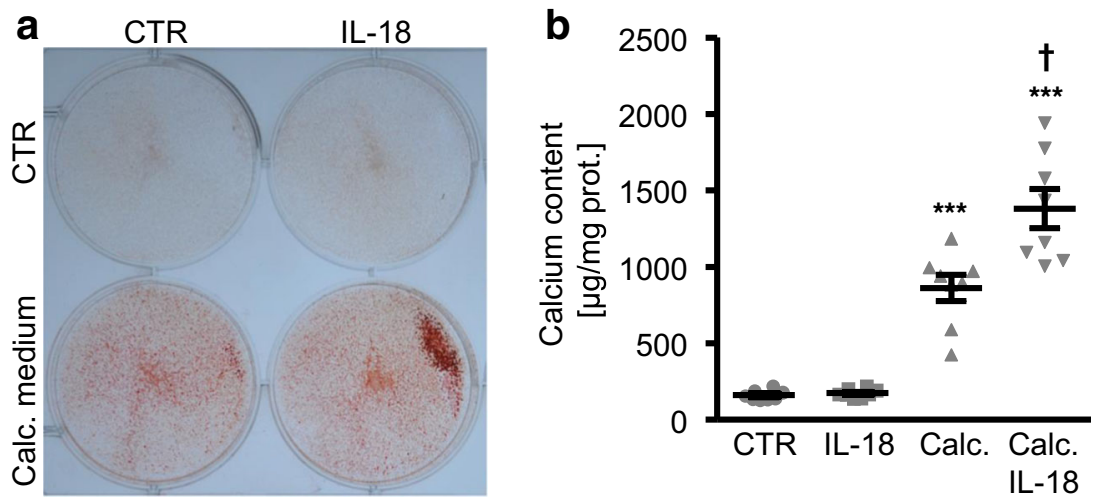

Fig. 3 Interleukin-18 aggravates phosphate-induced calcification of primary human aortic smooth muscle cells. a Representative original images $(n=4)$ showing Alizarin red staining in HAoSMCs following treatment for 11 days with control or with calcification medium (calc. medium) without or with additional treatment with $10 \mathrm{ng} / \mathrm{ml}$ recombinant human interleukin-18 protein (IL-18). The calcified areas are shown as red staining. b Scatter dot plots and arithmetic means \pm SEM $(n=8 ; \mu \mathrm{g} / \mathrm{mg}$

protein) of calcium content in HAoSMCs following treatment for 11 days with control or with calcification medium (calc.) without or with additional treatment with $10 \mathrm{ng} / \mathrm{ml}$ recombinant human interleukin- 18 protein (IL-18). $* * *(p<0.001)$ statistically significant vs. control-treated HAoSMCs; $\dagger(p<0.05)$ statistically significant vs. HAoSMCs treated with calcification medium alone 
performed at different passages of the cells. Normality was tested with Shapiro-Wilk test. Non-normal datasets were transformed (log) prior to statistical testing to provide normality according to Shapiro-Wilk test. Statistical testing was performed by one-way ANOVA followed by Tukey test for homoscedastic data or Games-Howell test for heteroscedastic data. Non-normal data were tested by the Steel-Dwass method. $P<0.05$ was considered statistically significant.
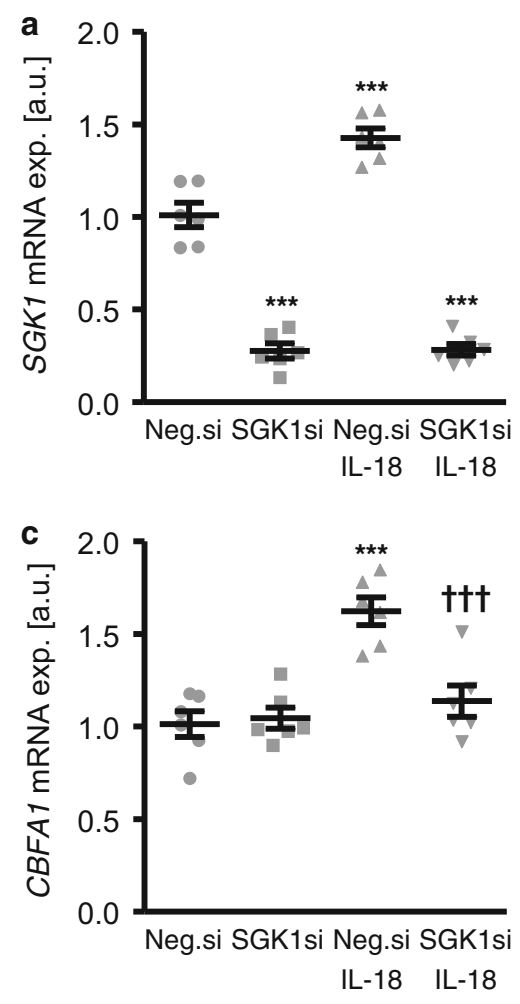

\section{Results}

To investigate the effects of IL-18 on SGK1 expression in VSMCs, primary human aortic smooth muscle cells (HAoSMCs) were treated with recombinant human IL-18 protein. As shown in Fig. 1a, SGK1 protein abundance increased in HAoSMCs after $5 \mathrm{~min}$ and remained high up to $24 \mathrm{~h}$ following IL-18 treatment. IL-18 upregulated $S G K 1$ mRNA
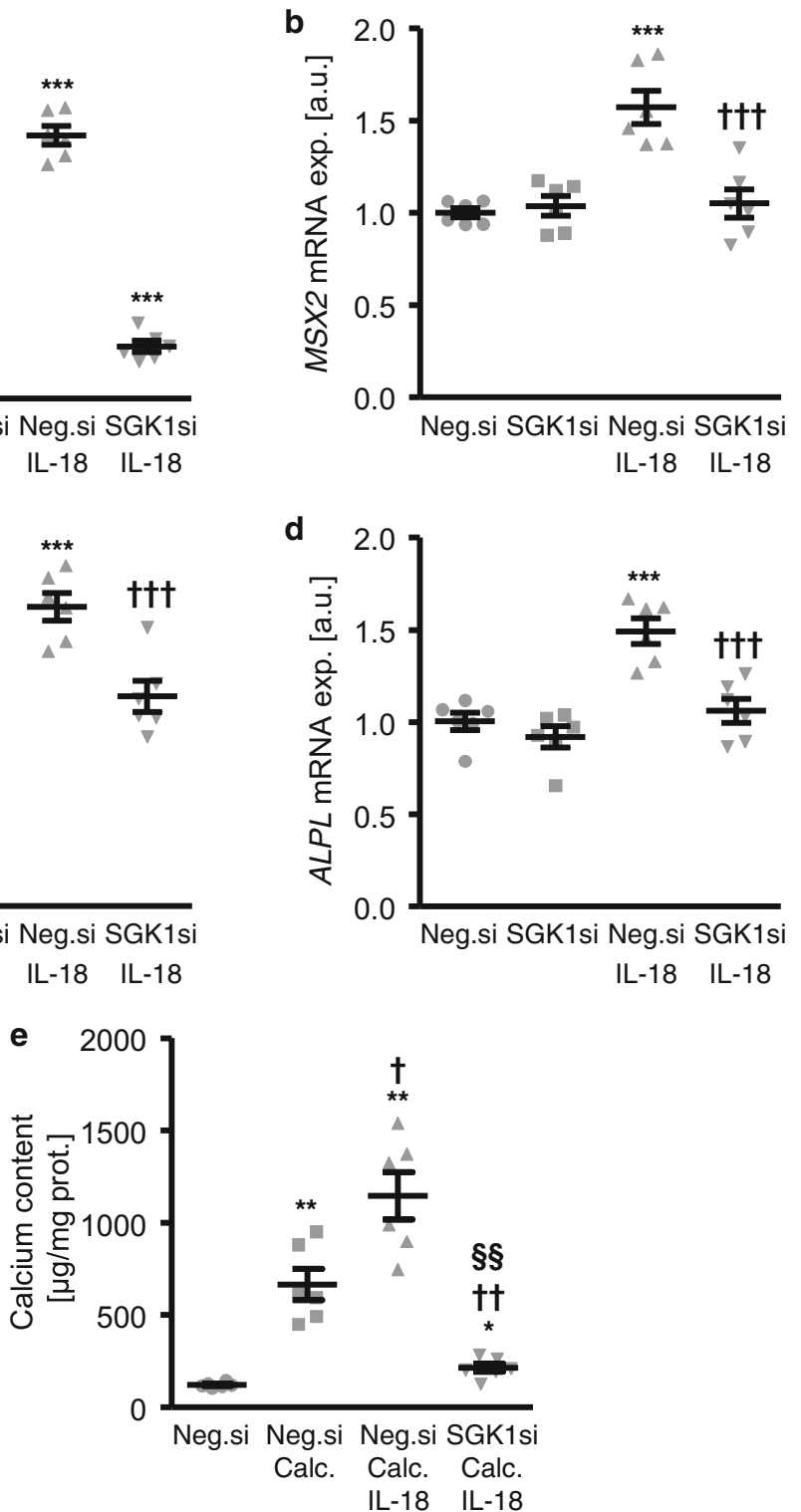

Fig. 4 Silencing of SGK1 blunts interleukin-18-induced osteogenic markers expression and calcification of primary human aortic smooth muscle cells. a-d Scatter dot plots and arithmetic means $\pm \operatorname{SEM}(n=6$, arbitrary units, a.u.) of $S G K 1$ (a), MSX2 (b), CBFA1 (c), and ALPL (d) relative mRNA expression in HAoSMCs following silencing for $48 \mathrm{~h}$ with negative control siRNA (neg.si) or SGK1 siRNA (SGK1si) without or with additional treatment for $24 \mathrm{~h}$ with $10 \mathrm{ng} / \mathrm{ml}$ recombinant human interleukin-18 protein (IL-18). $* * *(p<0.001)$ statistically significant vs. neg.si-silenced HAoSMCs; $\dagger \dagger(p<0.001)$ statistically significant vs. neg.si-silenced and IL-18-treated HAoSMCs. e Scatter dot plots and arithmetic means \pm SEM $(n=6 ; \mu \mathrm{g} / \mathrm{mg}$ protein) of calcium content in HAoSMCs following 11 days of silencing with negative control siRNA (neg.si) or SGK1 siRNA (SGK1si) and additional treatment with control or with calcification medium (calc.) without or with additional treatment with $10 \mathrm{ng} / \mathrm{ml}$ recombinant human interleukin-18 protein (IL-18). $*(p<0.05), * *(p<0.01)$ statistically significant vs. neg.si-silenced silenced and calcification medium alone-treated HAoSMCs; $\S \S(p<0.01)$ statistically significant vs. neg.si-silenced and calcification medium with IL-18-treated HAoSMCs HAoSMCs; $\dagger(p<0.05), \dagger \dagger(p<0.01)$ statistically significant vs. neg.si- 


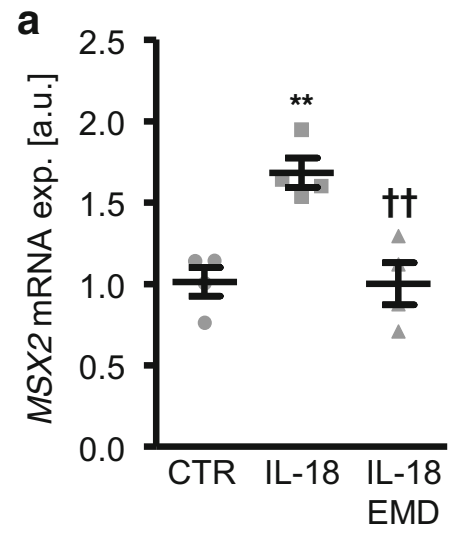

Fig. 5 SGK1 inhibition suppresses interleukin-18-induced osteogenic markers expression in primary human aortic smooth muscle cells. a-c Scatter dot plots and arithmetic means $\pm \operatorname{SEM}(n=4$, a.u.) of $M S X 2$ (a), $C B F A 1$ (b), and ALPL (c) relative mRNA expression in HAoSMCs following treatment for $24 \mathrm{~h}$ with control (CTR) or with $10 \mathrm{ng} / \mathrm{ml}$

expression in HAoSMCs in a concentration-dependent manner (Fig. 1b). These effects reached statistical significance at $10 \mathrm{ng} / \mathrm{ml}$ IL-18 concentration.

Similarly, IL-18 treatment dose-dependently increased the mRNA expression of the osteogenic transcription factors

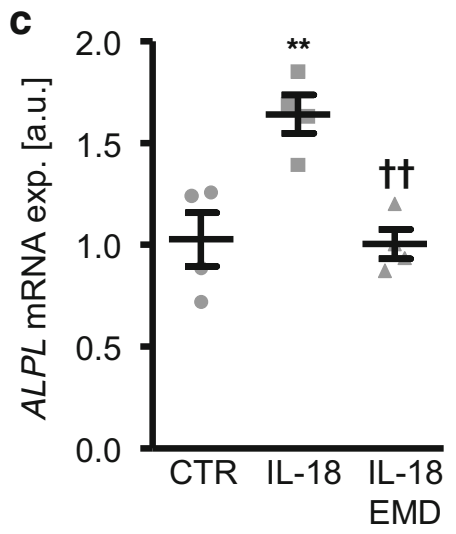

recombinant human interleukin-18 protein (IL-18) without or with additional treatment with $50 \mu \mathrm{M}$ SGK1 inhibitor EMD638683 (EMD). $* *(p<0.01)$ statistically significant vs. control-treated HAoSMCs; $\dagger(p<0.05), \dagger \dagger(p<0.01)$ statistically significant vs. IL-18 alone-treated HAoSMCs

MSX2 and CBFA1 (Fig. 1c, d) and of the osteogenic enzyme ALPL (Fig. 1e) in HAoSMCs, as markers of osteo-/ chondrogenic transdifferentiation. Thus, the increased SGK1 expression in IL-18 treated HAoSMCs was paralleled by increased osteo-/chondrogenic transdifferentiation.
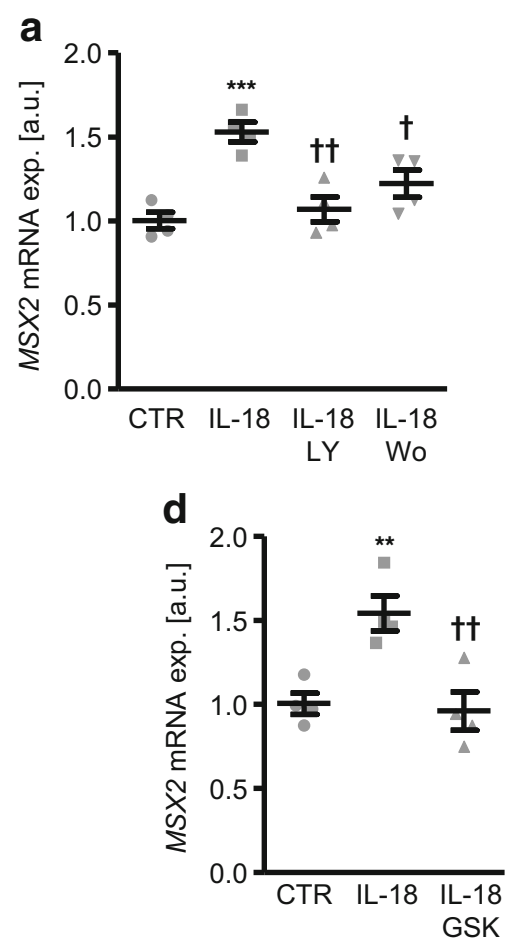

Fig. 6 Interleukin-18-induced osteo-/chondrogenic markers expression is suppressed by inhibition of PI3K pathway in primary human aortic smooth muscle cells. a Scatter dot plots and arithmetic means \pm SEM ( $n=4$; a.u.) of $M S X 2$ (a), CBFA1 (b), and $A L P L$ (c) relative mRNA expression in HAoSMCs following treatment for $24 \mathrm{~h}$ with control (CTR) or with $10 \mathrm{ng} / \mathrm{ml}$ recombinant human interleukin-18 protein (IL18) without or with additional treatment with the PI3K inhibitors $1 \mu \mathrm{M}$ LY294002 (LY) or $100 \mathrm{nM}$ wortmannin (Wo). Scatter dot plots and
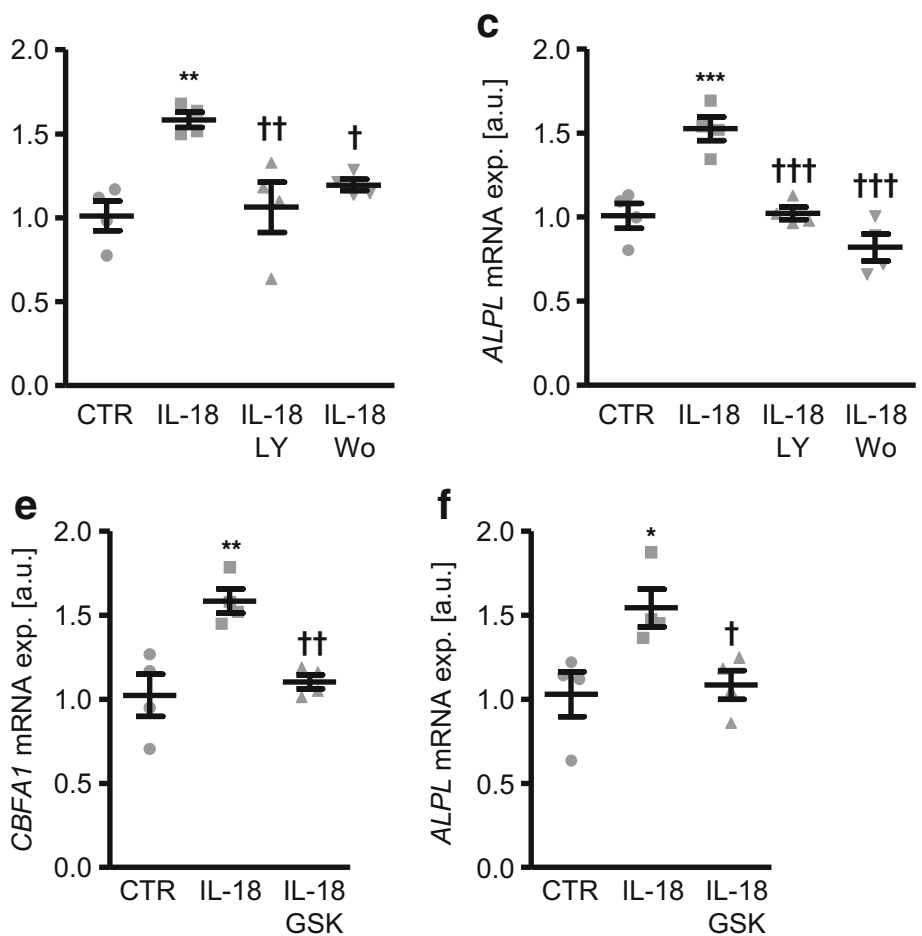

arithmetic means $\pm \operatorname{SEM}(n=4$; a.u.) of $M S X 2$ (d), CBFAl (e), and $A L P L$ (f) relative mRNA expression in HAoSMCs following treatment for $24 \mathrm{~h}$ with control (CTR) or with $10 \mathrm{ng} / \mathrm{ml}$ recombinant human interleukin-18 protein (IL-18) without or with additional treatment with $1 \mu \mathrm{M}$ PDK1 inhibitor GSK2334470 (GSK). * $(p<0.05), * *(p<0.01)$, $* * *(p<0.001)$ statistically significant vs. control-treated HAoSMCs; $\dagger(p<0.05), \dagger \dagger(p<0.01), \dagger+(p<0.001)$ statistically significant vs. HAoSMCs treated with IL-18 alone 
Next, we explored the effects of IL-18 on SGK1 expression and osteogenic signaling in HAoSMCs during high phosphate conditions. As shown in Fig. 2a, phosphate treatment upregulated SGK1 mRNA expression in HAoSMCs, an effect significantly augmented by additional treatment with IL-18. Moreover, the phosphate-induced osteogenic markers $M S X 2$, CBFAl, and ALPL mRNA expression (Fig. 2b-d) as well as ALPL activity (Fig. 2e) in HAoSMCs were significantly enhanced by IL-18 treatment. Alizarin red staining (Fig. 3a) and quantification of calcium deposition (Fig. 3b) in HAoSMCs revealed extensive calcification following treatment with calcification medium, effects again significantly aggravated by additional treatment with IL-18. Taken together, IL-18 augmented phosphate-induced SGK1 expression, osteogenic signaling, and calcification of HAoSMCs.

To investigate the possible involvement of SGK1 in IL-18induced osteo-/chondrogenic transdifferentiation of VSMCs, the endogenous expression of SGK1 was suppressed by silencing of the $S G K 1$ gene in HAoSMCs followed by additional treatment without or with IL-18. As a result, $S G K 1 \mathrm{mRNA}$ expression was significantly lower in SGK1 siRNA transfected HAoSMCs as compared to negative control siRNA silenced HAoSMCs (Fig. 4a). IL-18 treatment upregulated $S G K 1$ mRNA expression in negative control silenced HAoSMCs. The IL-18-induced mRNA expression of MSX2, $C B F A 1$, and $A L P L$ in negative control silenced HAoSMCs was significantly blunted in SGK1 silenced HAoSMCs (Fig. 4b-d). Furthermore, the augmentation of HAoSMCs calcification by IL-18 in the presence of calcification medium was reversed by SGK1 knockdown (Fig. 4e). In accordance with the previous observations showing protective effects of SGK1 inhibition during high phosphate conditions, silencing of SGK1 significantly inhibited calcium deposition in HAoSMCs beyond counteracting the procalcific effects of IL-18. Taken together, the procalcific effects of IL-18 in HAoSMCs were, at least in part, dependent on SGK1.

The involvement of SGK1 in IL-18-induced osteo-/ chondrogenic transdifferentiation of VSMCs was confirmed by treatment of HAoSMCs with IL-18 in the presence or absence of the SGK1 specific inhibitor EMD638683. As shown in Fig. 5a-c, SGK1 inhibitor EMD638683 similarly suppressed the IL-18-induced upregulation of $M S X 2$, CBFA1, and $A L P L$ mRNA expression in HAoSMCs.

Additional experiments were performed to elucidate the regulation of SGK1-dependent osteogenic signaling in IL18 treated HAoSMCs. To this end, the roles of phosphatidylinositol-4,5-bisphosphate 3 kinase (PI3K) and 3phosphoinositide-dependent protein kinase 1 (PDK1), critical upstream kinases in SGK1 regulation were investigated. As shown in Fig. 6a-c, the upregulation of $M S X 2$, CBFAl, and ALPL mRNA expression following treatment with IL-18 was significantly inhibited in the presence of either PI3K inhibitors LY294002 or wortmannin. In

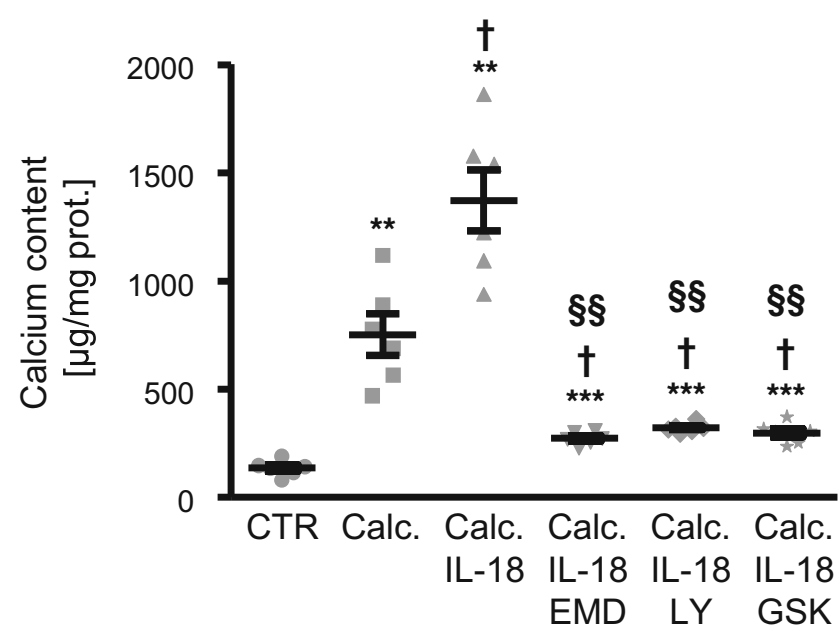

Fig. 7 Inhibition of SGK1 or PI3K pathway blunt the effects of interleukin-18 on calcification of primary human aortic smooth muscle cells. Scatter dot plots and arithmetic means \pm SEM $(n=6 ; \mu \mathrm{g} / \mathrm{mg}$ protein) of calcium content in HAoSMCs following treatment for 11 days with control or with calcification medium (calc.) without or with additional treatment with $10 \mathrm{ng} / \mathrm{ml}$ recombinant human interleukin- 18 protein (IL-18) alone or together with $50 \mu \mathrm{M}$ SGK1 inhibitor EMD638683 (EMD), $1 \mu \mathrm{M}$ PI3K inhibitor LY294002 (LY), or $1 \mu \mathrm{M}$ PDK1 inhibitor GSK2334470 (GSK). $* *(p<0.01), * * *(p<0.001)$ statistically significant vs. control-treated HAoSMCs; $\dagger(p<0.05)$ statistically significant vs. calcification medium alone-treated HAoSMCs; $\S \S(p<0.01)$ statistically significant vs. calcification medium with IL-18 alone-treated HAoSMCs

addition, IL-18-induced osteogenic markers mRNA expression was suppressed by additional treatment with the PDK1 inhibitor GSK2334470 (Fig. 6d-f). Thus, IL-18induced osteo-/chondrogenic signaling in VSMCs involved PI3K pathway activation. Accordingly, pharmacological inhibition of SGK1, PI3K, or PDK1, all suppressed calcium deposition in HAoSMCs triggered by calcification medium supplemented with IL-18 (Fig. 7).

\section{Discussion}

The present study discloses a novel key role of SGK1 in the signaling of IL-18-induced osteo-/chondrogenic transdifferentiation of VSMCs in-vitro. IL-18 upregulates SGK1 mRNA expression in VSMCs while silencing or pharmacological inhibition of SGK1 suppresses IL-18-induced osteogenic markers expression, indicative of increased osteo-/chondrogenic transdifferentiation (Fig. 8).

IL-18, a pro-inflammatory cytokine from the IL-1 cytokine family [17], is produced by various cells including osteoblasts [47], chondrocytes [38], and VSMCs [17]. IL-18 induces cellular inflammatory responses by binding to the IL-18 receptor [37]. VSMCs express a functional IL-18 receptor [17, 48]. Conversely, inflammatory processes upregulate IL-18 expression [14]. Increased plasma IL-18 levels are frequently observed in CKD patients $[12,16,62]$. IL-18 is involved in the 


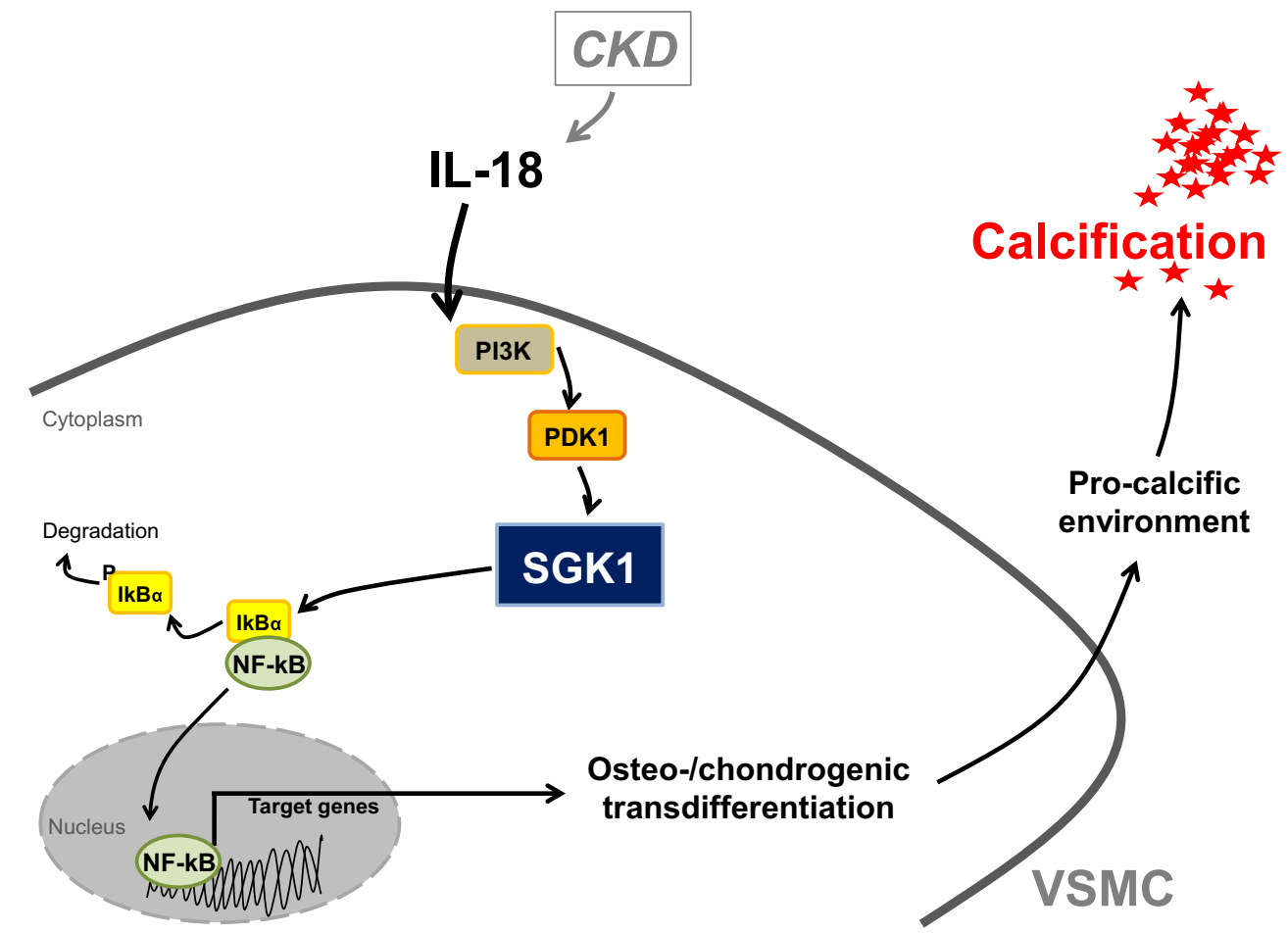

Fig. 8 Schematic illustration of SGK1-dependent IL-18-induced VSMC calcification. CKD increases circulating IL-18 levels $[12,16]$. In VSMCs, IL-18 may activate PI3K/PDK1 signaling to increase the expression and activity of SGK1. Further, SGK1 may induce transcriptional activation of NF-kB via phosphorylation-dependent ubiquitination and degradation of $\mathrm{IkB} \alpha[25]$ and, thus, the expression of NF-kB target genes to promote osteo-/chondrogenic transdifferentiation of VSMCs [58]. The osteo-/

progression of CKD [46, 51] and its related complications including vascular calcification [46, 62]. Similar to previous reports [62], our observations show that IL-18 treatment enhances phosphate-induced osteo-/chondrogenic transdifferentiation and calcification of VSMCs. In addition, IL-18 treatment alone is able to induce the expression of osteogenic markers in primary human aortic VSMCs.

The procalcific effects of IL-18 are mediated, at least in part, by SGK1. IL-18 upregulates SGK1 expression and augments phosphate-induced SGK1 expression in VSMCs. Excessive SGK1 is sufficient to promote osteo-/chondrogenic transdifferentiation of VSMCs via NF-kB activation [58] and NF-kB activity can be induced by IL-18 [24, 42, 50, 60]. SGK1 similarly plays a key role in vascular inflammation during atherogenesis via activation of NF-kB [7]. We could show here that silencing or pharmacological inhibition of SGK1 in VSMCs is able to suppress IL-18-induced osteogenic markers expression and calcium deposition, suggesting that SGK1 is a key factor in the signaling leading to osteo-/ chondrogenic transdifferentiation and calcification of VSMCs during conditions of high IL-18 levels.

Moreover, IL-18 is able to activate PI3K-dependent signaling in various cell types $[8,61,63]$ including VSMCs [40], while chondrogenic transdifferentiation of VSMCs induces a procalcific environment causing vascular calcification (CKD, chronic kidney disease; IL18, interleukin 18; PI3K, phosphatidylinositol-4,5-bisphosphate 3 kinase; PDK1, 3-phosphoinositide-dependent protein kinase 1; SGK1, serumand glucocorticoid-inducible kinase 1; NF-kB, nuclear factor "kappalight-chain-enhancer" of activated B-cells; $\mathrm{IkB} \alpha$, nuclear factor of kappa light polypeptide gene enhancer in B cells inhibitor, alpha)

PI3K activation leads to increased expression and activity of SGK1 [6, 13, 19, 25, 30]. Accordingly, PI3K and PDK1 inhibition suppresses IL-18-dependent osteoinduction in VSMCs.

The present observations identify SGK1 regulation as the key mechanism of IL-18-induced osteo-/chondrogenic transdifferentiation of VSMCs. However, other effects may contribute to the procalcific effects of IL-18 in VSMCs. TRPM7 is a ubiquitously expressed $\mathrm{Mg}^{2+}$-permeable ion channel [49] with a complex role during vascular calcification [36], which has been suggested to contribute to the effects of IL-18 [62]. SGK1 is able to enhance TRPM7 expression [49]. Thus, TRPM7 expression may also be a downstream product in the SGK1-dependent signaling during calcifying conditions.

Taken together, SGK1 appears critically important in the progression of vascular calcification during inflammatory conditions with high IL-18 levels such as CKD [12, $16,62]$. In addition, SGK1 mediates the induction of osteo-/chondrogenic transdifferentiation and, thus, vascular calcification by other pathological factors such as hyperphosphatemia or mineralocorticoid excess [58]. Thus, SGK1 may be a central key regulator in the signaling pathways mediating vascular calcification during various pathological conditions, including inflammation. 
Therefore, SGK1 inhibition may be a feasible therapeutic target to reduce the progression of vascular calcification triggered by complex conditions such as CKD [28, 29, 35, 44]. Moreover, SGK1 inhibition may potentially have an overall protective effect during cardiovascular or renal disease progression [10, 25, 27, 30, 55].

In conclusion, IL-18 upregulates SGK1 expression in VSMCs and SGK1 participates in the intracellular signaling mediating the IL-18-induced osteo-/chondrogenic transdifferentiation of VSMCs. Thus, SGK1 inhibition may be beneficial in reducing the progression of medial vascular calcification during vascular inflammatory conditions such as CKD.

Author contributions J.V. and I.A. designed research; N.S., T.T.D.L., and I.A. performed experiments; F.L., B.P., J.V., and I.A. analyzed and interpreted data; J.V. and I.A. wrote the manuscript with comments and edits from all authors.

Funding Information Open access funding provided by Johannes Kepler University Linz. This work was supported by the Berlin Institute of Health (BIH) Translational Postdoc Grant, the Deutsche Forschungsgemeinschaft (AL2054/1-1; VO2259/2-1), the European Union Seventh Framework Programme (FP7/2007-2013-603288-SysVasc), and the Else KrönerFresenius-Stiftung and the DZHK (German Centre for Cardiovascular Research).

\section{Compliance with ethical standards}

Conflict of interest The authors declare that they have no conflict of interest.

Open Access This article is distributed under the terms of the Creative Commons Attribution 4.0 International License (http:// creativecommons.org/licenses/by/4.0/), which permits unrestricted use, distribution, and reproduction in any medium, provided you give appropriate credit to the original author(s) and the source, provide a link to the Creative Commons license, and indicate if changes were made.

Publisher's note Springer Nature remains neutral with regard to jurisdictional claims in published maps and institutional affiliations.

\section{References}

1. Alesutan I, Feger M, Pakladok T, Mia S, Ahmed MS, Voelkl J, Lang F (2013) 25-Hydroxyvitamin D3 1-alpha-hydroxylasedependent stimulation of renal klotho expression by spironolactone. Kidney Blood Press Res 37:475-487. https://doi.org/10.1159/ 000355728

2. Alesutan I, Musculus K, Castor T, Alzoubi K, Voelkl J, Lang F (2015) Inhibition of phosphate-induced vascular smooth muscle cell osteo-/chondrogenic signaling and calcification by bafilomycin A1 and methylamine. Kidney Blood Press Res 40:490-499. https:// doi.org/10.1159/000368524

3. Alesutan I, Feger M, Tuffaha R, Castor T, Musculus K, Buehling SS, Heine CL, Kuro OM, Pieske B, Schmidt K, Tomaschitz A, Maerz W, Pilz S, Meinitzer A, Voelkl J, Lang F (2016) Augmentation of phosphate-induced osteo-/chondrogenic transformation of vascular smooth muscle cells by homoarginine. Cardiovasc Res 110:408-418. https://doi.org/10.1093/cvr/cvw062

4. Alesutan I, Tuffaha R, Auer T, Feger M, Pieske B, Lang F, Voelk1 J (2017) Inhibition of osteo/chondrogenic transformation of vascular smooth muscle cells by $\mathrm{MgCl} 2$ via calcium-sensing receptor. $\mathrm{J}$ Hypertens 35:523-532. https://doi.org/10.1097/HJH. 0000000000001202

5. Alesutan I, Voelk1 J, Feger M, Kratschmar DV, Castor T, Mia S, Sacherer M, Viereck R, Borst O, Leibrock C, Gawaz M, Kuro OM, Pilz S, Tomaschitz A, Odermatt A, Pieske B, Wagner CA, Lang F (2017) Involvement of vascular aldosterone synthase in phosphateinduced osteogenic transformation of vascular smooth muscle cells. Sci Rep 7:2059. https://doi.org/10.1038/s41598-017-01882-2

6. BelAiba RS, Djordjevic T, Bonello S, Artunc F, Lang F, Hess J, Gorlach A (2006) The serum- and glucocorticoid-inducible kinase Sgk-1 is involved in pulmonary vascular remodeling: role in redoxsensitive regulation of tissue factor by thrombin. Circ Res 98:828836. https://doi.org/10.1161/01.RES.0000210539.54861.27

7. Borst O, Schaub M, Walker B, Schmid E, Munzer P, Voelkl J, Alesutan I, Rodriguez JM, Vogel S, Schoenberger T, Metzger K, Rath D, Umbach A, Kuhl D, Muller II, Seizer P, Geisler T, Gawaz M, Lang F (2015) Pivotal role of serum- and glucocorticoidinducible kinase 1 in vascular inflammation and atherogenesis. Arterioscler Thromb Vasc Biol 35:547-557. https://doi.org/10. 1161/ATVBAHA.114.304454

8. Chandrasekar B, Mummidi S, Claycomb WC, Mestril R, Nemer M (2005) Interleukin-18 is a pro-hypertrophic cytokine that acts through a phosphatidylinositol 3-kinase-phosphoinositidedependent kinase-1-Akt-GATA4 signaling pathway in cardiomyocytes. J Biol Chem 280:4553-4567. https://doi.org/10. 1074/jbc.M411787200

9. Chen NX, Moe SM (2015) Pathophysiology of vascular calcification. Curr Osteoporos Rep 13:372-380. https://doi.org/10.1007/ s11914-015-0293-9

10. Cheng J, Truong LD, Wu X, Kuhl D, Lang F, Du J (2010) Serumand glucocorticoid-regulated kinase 1 is upregulated following unilateral ureteral obstruction causing epithelial-mesenchymal transition. Kidney Int 78:668-678. https://doi.org/10.1038/ki.2010.214

11. Cheng SL, Behrmann A, Shao JS, Ramachandran B, Krchma K, Bello Arredondo Y, Kovacs A, Mead M, Maxson R, Towler DA (2014) Targeted reduction of vascular Msx1 and Msx2 mitigates arteriosclerotic calcification and aortic stiffness in LDLR-deficient mice fed diabetogenic diets. Diabetes 63:4326-4337. https://doi. org/10.2337/db14-0326

12. Chiang CK, Hsu SP, Pai MF, Peng YS, Ho TI, Liu SH, Hung KY, Tsai TJ, Hsieh BS (2005) Plasma interleukin-18 levels in chronic renal failure and continuous ambulatory peritoneal dialysis. Blood Purif 23:144-148. https://doi.org/10.1159/000083620

13. Di Cristofano A (2017) SGK1: the dark side of PI3K signaling. Curr Top Dev Biol 123:49-71. https://doi.org/10.1016/bs.ctdb. 2016.11.006

14. Dinarello CA (1999) Interleukin-18. Methods 19:121-132. https:// doi.org/10.1006/meth.1999.0837

15. Gan W, Ren J, Li T, Lv S, Li C, Liu Z, Yang M (2018) The SGK1 inhibitor EMD638683, prevents Angiotensin II-induced cardiac inflammation and fibrosis by blocking NLRP3 inflammasome activation. Biochim Biophys Acta 1864:1-10. https://doi.org/10.1016/ j.bbadis.2017.10.001

16. Gangemi S, Mallamace A, Minciullo PL, Santoro D, Merendino RA, Savica V, Bellinghieri G (2002) Involvement of interleukin-18 in patients on maintenance haemodialysis. Am J Nephrol 22:417421. https://doi.org/10.1159/000065269

17. Gerdes N, Sukhova GK, Libby P, Reynolds RS, Young JL, Schonbeck U (2002) Expression of interleukin (IL)-18 and functional IL-18 receptor on human vascular endothelial cells, smooth 
muscle cells, and macrophages: implications for atherogenesis. $\mathrm{J}$ Exp Med 195:245-257

18. Giachelli CM (2009) The emerging role of phosphate in vascular calcification. Kidney Int 75:890-897. https://doi.org/10.1038/ki. 2008.644

19. Gonzalez-Robayna IJ, Falender AE, Ochsner S, Firestone GL, Richards JS (2000) Follicle-stimulating hormone (FSH) stimulates phosphorylation and activation of protein kinase $\mathrm{B}(\mathrm{PKB} / \mathrm{Akt})$ and serum and glucocorticoid-induced kinase (Sgk): evidence for a kinase-independent signaling by FSH in granulosa cells. Mol Endocrinol 14:1283-1300. https://doi.org/10.1210/mend.14.8. 0500

20. Guerin AP, Blacher J, Pannier B, Marchais SJ, Safar ME, London GM (2001) Impact of aortic stiffness attenuation on survival of patients in end-stage renal failure. Circulation 103:987-992

21. Gukovsky I, Cheng JH, Nam KJ, Lee OT, Lugea A, Fischer L, Penninger JM, Pandol SJ, Gukovskaya AS (2004) Phosphatidylinositide 3-kinase gamma regulates key pathologic responses to cholecystokinin in pancreatic acinar cells. Gastroenterology 126:554-566

22. Inoue K, Leng T, Yang T, Zeng Z, Ueki T, Xiong ZG (2016) Role of serum- and glucocorticoid-inducible kinases in stroke. J Neurochem 138:354-361. https://doi.org/10.1111/jnc.13650

23. Kiu Weber CI, Duchateau-Nguyen G, Solier C, Schell-Steven A, Hermosilla R, Nogoceke E, Block G (2014) Cardiovascular risk markers associated with arterial calcification in patients with chronic kidney disease Stages 3 and 4. Clin Kidney J 7:167-173. https:// doi.org/10.1093/ckj/sfu017

24. Kojima H, Aizawa Y, Yanai Y, Nagaoka K, Takeuchi M, Ohta T, Ikegami H, Ikeda M, Kurimoto M (1999) An essential role for NFkappa B in IL-18-induced IFN-gamma expression in KG-1 cells. J Immunol 162:5063-5069

25. Lang F, Voelkl J (2013) Therapeutic potential of serum and glucocorticoid inducible kinase inhibition. Expert Opin Investig Drugs 22:701-714. https://doi.org/10.1517/13543784.2013.778971

26. Lang F, Gorlach A, Vallon V (2009) Targeting SGK1 in diabetes. Expert Opin Ther Targets 13:1303-1311. https://doi.org/10.1517/ 14728220903260807

27. Lang F, Huang DY, Vallon V (2010) SGK, renal function and hypertension. J Nephrol 23(Suppl 16):S124-S129

28. Lang F, Ritz E, Voelkl J, Alesutan I (2013) Vascular calcification-is aldosterone a culprit? Nephrol Dial Transplant 28:1080-1084. https://doi.org/10.1093/ndt/gft041

29. Lang F, Ritz E, Alesutan I, Voelkl J (2014) Impact of aldosterone on osteoinductive signaling and vascular calcification. Nephron Physiol 128:40-45. https://doi.org/10.1159/000368268

30. Lang F, Stournaras C, Alesutan I (2014) Regulation of transport across cell membranes by the serum- and glucocorticoid-inducible kinase SGK1. Mol Membr Biol 31:29-36. https://doi.org/10.3109/ 09687688.2013.874598

31. Lang F, Leibrock C, Pelzl L, Gawaz M, Pieske B, Alesutan I, Voelkl J (2018) Therapeutic interference with vascular CalcificationLessons From Klotho-Hypomorphic Mice and Beyond. Front Endocrinol (Lausanne) 9:207. https://doi.org/10.3389/fendo.2018. 00207

32. Lanzer P, Boehm M, Sorribas V, Thiriet M, Janzen J, Zeller T, St Hilaire C, Shanahan C (2014) Medial vascular calcification revisited: review and perspectives. Eur Heart J 35:1515-1525. https://doi.org/10.1093/eurheartj/ehu163

33. Leibrock CB, Alesutan I, Voelkl J, Pakladok T, Michael D, Schleicher E, Kamyabi-Moghaddam Z, Quintanilla-Martinez L, Kuro-o M, Lang F (2015) NH4Cl treatment prevents tissue calcification in klotho deficiency. J Am Soc Nephrol 26:2423-2433. https://doi.org/10.1681/ASN.2014030230

34. Luong TTD, Schelski N, Boehme B, Makridakis M, Vlahou A, Lang F, Pieske B, Alesutan I, Voelkl J (2018) Fibulin-3 attenuates phosphate-induced vascular smooth muscle cell calcification by inhibition of oxidative stress. Cell Physiol Biochem 46:13051316. https://doi.org/10.1159/000489144

35. Mizobuchi M, Towler D, Slatopolsky E (2009) Vascular calcification: the killer of patients with chronic kidney disease. J Am Soc Nephrol 20:1453-1464. https://doi.org/10.1681/ASN.2008070692

36. Montezano AC, Zimmerman D, Yusuf H, Burger D, Chignalia AZ, Wadhera V, van Leeuwen FN, Touyz RM (2010) Vascular smooth muscle cell differentiation to an osteogenic phenotype involves TRPM7 modulation by magnesium. Hypertension 56:453-462. https://doi.org/10.1161/HYPERTENSIONAHA.110.152058

37. O'Brien LC, Mezzaroma E, Van Tassell BW, Marchetti C, Carbone S, Abbate A, Toldo S (2014) Interleukin-18 as a therapeutic target in acute myocardial infarction and heart failure. Mol Med 20:221229. https://doi.org/10.2119/molmed.2014.00034

38. Olee T, Hashimoto S, Quach J, Lotz M (1999) IL-18 is produced by articular chondrocytes and induces proinflammatory and catabolic responses. J Immunol 162:1096-1100

39. Paloian NJ, Giachelli CM (2014) A current understanding of vascular calcification in CKD. Am J Physiol Renal Physiol 307:F891F900. https://doi.org/10.1152/ajprenal.00163.2014

40. Reddy VS, Valente AJ, Delafontaine P, Chandrasekar B (2011) Interleukin-18/WNT1-inducible signaling pathway protein-1 signaling mediates human saphenous vein smooth muscle cell proliferation. J Cell Physiol 226:3303-3315. https://doi.org/10.1002/jcp. 22676

41. Rennenberg RJ, Kessels AG, Schurgers LJ, van Engelshoven JM, de Leeuw PW, Kroon AA (2009) Vascular calcifications as a marker of increased cardiovascular risk: a meta-analysis. Vasc Health Risk Manag 5:185-197

42. Sahar S, Dwarakanath RS, Reddy MA, Lanting L, Todorov I, Natarajan R (2005) Angiotensin II enhances interleukin-18 mediated inflammatory gene expression in vascular smooth muscle cells: a novel cross-talk in the pathogenesis of atherosclerosis. Circ Res 96:1064-1071. https://doi.org/10.1161/01.RES. 0000168210.10358.f4

43. Sheen CR, Kuss P, Narisawa S, Yadav MC, Nigro J, Wang W, Chhea TN, Sergienko EA, Kapoor K, Jackson MR, Hoylaerts MF, Pinkerton AB, O'Neill WC, Millan JL (2015) Pathophysiological role of vascular smooth muscle alkaline phosphatase in medial artery calcification. J Bone Miner Res 30:824 836. https://doi.org/10.1002/jbmr.2420

44. Shroff R, Long DA, Shanahan C (2013) Mechanistic insights into vascular calcification in CKD. J Am Soc Nephrol 24:179-189. https://doi.org/10.1681/ASN.2011121191

45. Tuffaha R, Voelkl J, Pieske B, Lang F, Alesutan I (2018) Role of $\mathrm{PKB} / \mathrm{SGK}$-dependent phosphorylation of GSK-3alpha/beta in vascular calcification during cholecalciferol overload in mice. Biochem Biophys Res Commun 503:2068-2074. https://doi.org/ 10.1016/j.bbrc.2018.07.161

46. Turner CM, Arulkumaran N, Singer M, Unwin RJ, Tam FW (2014) Is the inflammasome a potential therapeutic target in renal disease? BMC Nephrol 15:21. https://doi.org/10.1186/1471-2369-15-21

47. Udagawa N, Horwood NJ, Elliott J, Mackay A, Owens J, Okamura H, Kurimoto M, Chambers TJ, Martin TJ, Gillespie MT (1997) Interleukin-18 (interferon-gamma-inducing factor) is produced by osteoblasts and acts via granulocyte/macrophage colonystimulating factor and not via interferon-gamma to inhibit osteoclast formation. J Exp Med 185:1005-1012

48. Valente AJ, Yoshida T, Izadpanah R, Delafontaine P, Siebenlist U, Chandrasekar B (2013) Interleukin-18 enhances IL-18R/Nox1 binding, and mediates TRAF3IP2-dependent smooth muscle cell migration. Inhibition by simvastatin. Cell Signal 25:1447-1456. https://doi.org/10.1016/j.cellsig.2013.03.007

49. Valinsky WC, Jolly A, Miquel P, Touyz RM, Shrier A (2016) Aldosterone upregulates transient receptor potential melastatin 7 
(TRPM7). J Biol Chem 291:20163-20172. https://doi.org/10.1074/ jbc.M116.735175

50. Victor AR, Nalin AP, Dong W, McClory S, Wei M, Mao C, Kladney RD, Youssef Y, Chan WK, Briercheck EL, Hughes T, Scoville SD, Pitarresi JR, Chen C, Manz S, Wu LC, Zhang J, Ostrowski MC, Freud AG, Leone GW, Caligiuri MA, Yu J (2017) IL-18 drives ILC3 proliferation and promotes IL-22 production via NF-kappaB. J Immunol 199:2333-2342. https://doi.org/10. 4049/jimmunol.1601554

51. Vilaysane A, Chun J, Seamone ME, Wang W, Chin R, Hirota S, Li Y, Clark SA, Tschopp J, Trpkov K, Hemmelgarn BR, Beck PL, Muruve DA (2010) The NLRP3 inflammasome promotes renal inflammation and contributes to CKD. J Am Soc Nephrol 21: 1732-1744. https://doi.org/10.1681/ASN.2010020143

52. Villa-Bellosta R, Millan A, Sorribas V (2011) Role of calciumphosphate deposition in vascular smooth muscle cell calcification. Am J Physiol Cell Physiol 300:C210-C220. https://doi.org/10. 1152/ajpcell.00229.2010

53. Voelk1 J, Lin Y, Alesutan I, Ahmed MS, Pasham V, Mia S, Gu S, Feger M, Saxena A, Metzler B, Kuhl D, Pichler BJ, Lang F (2012) Sgk1 sensitivity of $\mathrm{Na}(+) / \mathrm{H}(+)$ exchanger activity and cardiac remodeling following pressure overload. Basic Res Cardiol 107:236. https://doi.org/10.1007/s00395-011-0236-2

54. Voelk1 J, Alesutan I, Leibrock CB, Quintanilla-Martinez L, Kuhn V, Feger M, Mia S, Ahmed MS, Rosenblatt KP, Kuro OM, Lang F (2013) Spironolactone ameliorates PIT1-dependent vascular osteoinduction in klotho-hypomorphic mice. J Clin Invest 123: 812-822. https://doi.org/10.1172/JCI64093

55. Voelkl J, Mia S, Meissner A, Ahmed MS, Feger M, Elvira B, Walker B, Alessi DR, Alesutan I, Lang F (2013) PKB/SGK-resistant GSK-3 signaling following unilateral ureteral obstruction. Kidney Blood Press Res 38:156-164. https://doi.org/10.1159/000355763

56. Voelkl J, Pasham V, Ahmed MS, Walker B, Szteyn K, Kuhl D, Metzler B, Alesutan I, Lang F (2013) Sgk1-dependent stimulation of cardiac $\mathrm{Na}+\mathrm{H}+$ exchanger Nhe1 by dexamethasone. Cell Physiol Biochem 32:25-38. https://doi.org/10.1159/000350120

57. Voelk1 J, Castor T, Musculus K, Viereck R, Mia S, Feger M, Alesutan I, Lang F (2015) SGK1-sensitive regulation of cyclindependent kinase inhibitor 1B (p27) in cardiomyocyte hypertrophy. Cell Physiol Biochem 37:603-614. https://doi.org/10.1159/ 000430380

58. Voelk1 J, Luong TT, Tuffaha R, Musculus K, Auer T, Lian X, Daniel C, Zickler D, Boehme B, Sacherer M, Metzler B, Kuhl D, Gollasch M, Amann K, Muller DN, Pieske B, Lang F, Alesutan I (2018) SGK1 induces vascular smooth muscle cell calcification through NF-kappaB signaling. J Clin Invest 128:3024-3040. https://doi.org/10.1172/JCI96477

59. Voelkl J, Tuffaha R, Luong TTD, Zickler D, Masyout J, Feger M, Verheyen N, Blaschke F, Kuro OM, Tomaschitz A, Pilz S, Pasch A, Eckardt KU, Scherberich JE, Lang F, Pieske B, Alesutan I (2018) Zinc inhibits phosphate-induced vascular calcification through TNFAIP3-mediated suppression of NF-kappaB. J Am Soc Nephrol 29:1636-1648. https://doi.org/10.1681/ASN.2017050492

60. Weinstock JV, Blum A, Metwali A, Elliott D, Arsenescu R (2003) IL-18 and IL-12 signal through the NF-kappa B pathway to induce NK-1R expression on T cells. J Immunol 170:5003-5007

61. Yoo JK, Kwon H, Khil LY, Zhang L, Jun HS, Yoon JW (2005) IL18 induces monocyte chemotactic protein- 1 production in macrophages through the phosphatidylinositol 3-kinase/Akt and MEK/ ERK1/2 pathways. J Immunol 175:8280-8286

62. Zhang K, Zhang Y, Feng W, Chen R, Chen J, Touyz RM, Wang J, Huang H (2017) Interleukin-18 enhances vascular calcification and osteogenic differentiation of vascular smooth muscle cells through TRPM7 activation. Arterioscler Thromb Vasc Biol 37:1933-1943. https://doi.org/10.1161/ATVBAHA.117.309161

63. Zhou J, Ping FF, Lv WT, Feng JY, Shang J (2014) Interleukin-18 directly protects cortical neurons by activating PI3K/AKT/NFkappaB/CREB pathways. Cytokine 69:29-38. https://doi.org/10. 1016/j.cyto.2014.05.003 